\title{
A STUDY OF SURGICAL MANAGEMENT OF MALLEOLAR FRACTURES IN ADULTS
}

Srinivas Nagendra G¹, Prabhakar Venkataramana², Siddarth Mahesh ${ }^{3}$

\section{HOW TO CITE THIS ARTICLE:}

Srinivas Nagendra G, Prabhakar Venkataramana, Siddarth Mahesh. "A Study of Surgical Management of Malleolar Fractures in Adults". Journal of Evolution of Medical and Dental Sciences 2014; Vol. 3, Issue 12, March 24; Page: 2989-3005, DOI: 10.14260/jemds/2014/2234

ABSTRACT: BACKGROUND: In this age of road traffic accidents and sports activities the occurrence of malleolar fractures of the ankle are common. Malleolar fractures account for nearly $2 \%$ of all the fractures. OBJECTIVES: To clinically evaluate the, Rate of union, the functional outcome of the treatment, Complications, to compare the results of the study with the studies reported. DESIGN: prospective study. SETTING: Sapthagiri Medical College \& Hospital. Bangalore. METHODS: During the period of July 2012 to December 2013, thirty adults with malleolar fractures of the ankle were operated at Sapthagiri Medical College \& Hospital., Bangalore. They were treated by open reduction and internal fixation by one-third tubular plate or dynamic compression plate, tension band wiring, malleolar screws or a combination of these. The rating was done as per Weber's protocol. RESULTS: Acceptable results were obtained in twenty- five out of thirty patients, with $83.3 \%$ of the patients having excellent to good rating. Five patients (16.6\%) results were poor, because of pain on activity, restriction of range of motion at the ankle and subtalar joint, and restriction of activity. CONCLUSION: Surgical management of malleolar fractures of the ankle by open reduction and internal fixation remains the treatment of choice, to ensure anatomical joint restoration, union, and good function of the ankle joint.

KEYWORDS: tubular plate, dynamic compression plate, tension band wiring, malleolar screws, weber's.

INTRODUCTION: In this age of road traffic accidents and sports activities the occurrence of malleolar fractures of the ankle are common. Malleolar fractures account for nearly $2 \%$ of all the fractures ${ }^{1}$ In order to obtain anatomical joint restoration, malleolar fractures can be managed both conservatively and surgically. For most fractures surgical management by open reduction and internal fixation ensures anatomical joint restoration and union.

The advantages of open reduction and internal fixation (ORIF) are

- The normal relationship of ankle mortise can be restored. ${ }^{1}$

- Weight bearing alignment of the ankle at right angle to the longitudinal axis of the leg is achieved. ${ }^{1}$

- The contours of the articular surface can be achieved. ${ }^{1}$

- Prevents malunion, nonunion, post traumatic arthritis and alteration of joint kinetics. ${ }^{1,2}$

Injuries about the ankle joint cause destruction of not only the bony architecture but also often of the ligamentous and soft tissue components. ${ }^{1}$ Only slight variation from normal is compatible with good joint function.

Randomized, prospective studies have shown that better results are obtained with operative than non-operative treatment ${ }^{3}$.The present study is done to assess the functional outcome and 


\section{ORIGINAL ARTICLE}

complications following open reduction and internal fixation of malleolar fractures in adults and to compare with the previous studies.

MATERIALS AND METHODS: The clinical material for the study of surgical management of malleolar fractures of ankle in adults consists of 30 cases of fresh fractures of traumatic etiology meeting the inclusion and exclusion criteria, admitted to Sapthagiri Medical College \& Hospital., Bangalore Hospital, from July 2012 to December 2013.

\section{Inclusion Criteria:}

1. Patients 18 years and above.

2. Fresh fractures.

3. Simple and compound fractures.

4. Undisplaced fracture of medial malleolus in patients with high functional demands. ${ }^{1}$

5. Displaced fracture of medial malleolus. ${ }^{1}$

6. Fracture of lateral malleolus with more than $5 \mathrm{~mm}$ displacement. ${ }^{1}$

7. Danis- Weber Type B and Type C Fractures ${ }^{1}$.

8. Displaced bimalleolar fractures. ${ }^{1}$

9. Posterior malleolus fragment involving more than $25 \%$ of articular surface. ${ }^{1}$

10. Trimalleolar fractures. ${ }^{1}$

\section{Exclusion Criteria:}

1. Children

2. Epiphyseal injuries

3. Pathological fracture

4. Malunion

5. Non-union

6. Associated fractures of the tarsal bones and pilon fractures.

\section{PREOPERATIVE PLANNING:}

- Patients were kept fasting over night before surgery.

- Adequate amount of compatible blood was kept ready for any eventuality.

- The whole of the extremity below the umbilicus, including the genitalia was prepared when required

- A systemic antibiotic, usually a $3^{\text {rd }}$ generation cephalosporin was administered 1 hour before surgery.

\section{IMPLANT SELECTION:}

TYPE A: transverse fracture of the lateral malleolus below the syndesmosis with oblique fracture of medial malleolus

\section{IMPLANTS:}

1. Kirschner wires $1.6 \mathrm{~mm}$ diameter, and figure of eight tension band wires $1.2 \mathrm{~mm}$ diameter, for lateral malleolus with poor bone quality. For a larger fragment of lateral malleolus, one - third tubular plate 
2. $4.5 \mathrm{~mm}$ intramedullary lag screw if the bone stock is good.

3. $4.0 \mathrm{~mm}$ cancellous bone screws, or $4.5 \mathrm{~mm}$ cannulated screws as malleolar screws for medial malleolus. If fragment is small and comminuted tension band wiring is done.

TYPE B: Transsyndesmotic oblique fracture of lateral malleolus and fracture of the medial malleolus and rupture of tibiofibular or deltoid ligament.

\section{IMPLANTS:}

1. Contoured one third tubular plate for lateral malleolus. Preferably posterolateral plating (anti glide technique) is done

2. Oblique lateral malleolus fracture without comminution - 2 lag screws $1 \mathrm{cms}$ apart

3. If the fracture is transverse intramedullary nailing device done

4. $4.5 \mathrm{~mm}$ intramedullary lag screw if the bone stock is good.

5. $3.5 \mathrm{~mm}$ cortical screw as syndesmotic screw if necessary

6. $4 \mathrm{~mm}$ cancellous screw or $4.5 \mathrm{~mm}$ cannulated screws or tension band wiring for medial malleolus.

TYPE C: Suprasyndesmotic fibular fracture with medial malleolar fracture and disruption of the interosseous membrane or deltoid ligament rupture.

\section{IMPLANTS:}

1. One - third tubular plate, 8-12 holes for fibular fracture if plate extends below the plafond unicortical cancellous screws put

2. $3.5 \mathrm{~mm}$ dynamic compression plate in case of larger individuals.

3. 3.5 cortical screw as syndesmotic screw

4. $4.0 \mathrm{~mm}$ cancellous bone screws or $4.5 \mathrm{~mm}$ cannulated screws for the medial malleolar fracture

5. Kirschner wires. $1.6 \mathrm{~mm}$ diameter, and figure of eight tension band wire $1.2 \mathrm{~mm}$ diameter, for medial malleolar fracture when the fragment is small and comminuted.

\section{OPERATIVE TECHNIQUE:}

ANAESTHESIA: The patient is taken up for surgery under spinal anesthesia.

PATIENT POSITIONING: The patient is placed in supine position with the leg in slight internal rotation by placing sand bag beneath the buttock.

TORNIQUET: Tourniquet is applied and time is noted.

DRAPING: The ankle with the foot and leg is scrubbed with betadine scrub for 10 minutes. Painted with betadine solution and spirit. Draped with linen and opsite over the proposed incision site.

\section{APPROACHES:}

Anterolateral approach ${ }^{1}$

Anteromedial approach

Anteromedial approach for medial malleolus. (Colonna and Ralston approach) ${ }^{1}$

Postero lateral approach 


\section{POST- OPERATIVE MANAGEMENT:}

- The limb is elevated over a pillow.

- The patient is encouraged to move his toes.

- The blood pressure, pulse, temperature, soakage of dressing is observed.

- Parenteral antibiotics continued.

- On 3rd post- operative day, check dressing of wound is done; the condition of the wound is noted.

- Check x- ray is taken both is AP and Lateral views.

- From the $5^{\text {th }}$ post-operative day oral antibiotics are administered till the suture removal.

- Sutures are removed on the $12^{\text {th }}-14^{\text {th }}$ day.

- Patient is advised non weight bearing for 6 weeks and discharged with below knee POP cast.

- Partial weight bearing after 6 weeks till fracture unites. Physiotherapy is given during follow up.

- Regular OPD follow ups were done at 6weeks, 12weeks, 16weeks, 20weeks, till 6 months.

- The results were assessed based on.

1. Pain

2. Range of movement at the ankle and subtalar joint

3. Fracture union clinically and radiologically

4. Activity

5. Complication like infection, deformity and swelling

6. Rating as per Weber's protocol.

RESULTS: At the end of 6 months after complete rehabilitation and recovery, scoring and rating is done as per Weber's protocol. ${ }^{4}$

\section{Weber's Protocol for Rating Results of Treatment of Ankle Fractures:}

1. Pain

- No pain

- Slight pain with excess activity

- Mild pain with normal activity

- Pain with standing

- Pain at rest
- Nil

$-+$

$-++$

$-+++$

$-++++$
Rating

0

1

2

3

4

\section{ROM - Ankle}

- Full range ( DF- 0-30, PF - 0-45) (FR)

- Loss of motion , $10^{*}$

- Loss of motion $>10^{*}$ but DF till 95*

2

- Motion $<10^{*}$ but DF till 95*

3

- $\quad$ Stiff foot $(\mathrm{SF})$ 


\section{ORIGINAL ARTICLE}

\section{ROM - Subtalar joint}

- Full function ( Inv - 0-25, Ev-0-25) (FR) 0

- Slight diminution (SD) 1

- Limitation $<1 / 2$ of sound side $(L<1 / 2) \quad 2$

- Limitation $>1 / 2$ of sound side $(\mathrm{L}>1 / 2)$

- No motion (NM) 4

\section{Radiograph}

- Anatomically perfect no arthritis (AP NA). 0

- Anatomically perfect with slight calcification in ligaments, 1 no arthritis (AP NA C)

- Anatomical disruption of medial side (AD M) 2

- Anatomical disruption on lateral side with arthritis (AD-L- A). 3

- Step off in joint with arthritis (ST A). 4

\section{Activity}

- Fully perform job( FPJ) 0

- Normal work, Restriction in some strenuous activities ( NW RSA)1

- Normal work, limited in his activity ( NW LA) 2

- Partially disabled (PD) 3

- Totally disabled must change of job (TD) 4

\section{Complications}

- Infection(IN)

- Deformity(DE)

- Swelling(SW)

Rating: - Excellent - 0

- Good - 1 or 2

- Poor - 3 or more.

Statistical Methods: Descriptive statistical analysis has been carried out in the present study. $90 \%$ confidence interval has been computed to find the significance of outcome of surgical management in patients.

Statistical Software: The Statistical software namely SPSS 15.0, Stata 8.0, MedCalc 9.0.1 and Systat 11.0 were used for the analysis of the data and Microsoft word and Excel have been used to generate graphs, tables etc.

DISCUSSION: During our study, we learnt that accurate anatomical reduction of ankle fracture is not sufficient, it was also necessary to maintain reduction till complete union occurs. This was best achieved by internal fixation. This is supported by the study of Mitchell where he said anatomical 
reduction of displaced malleolar fractures, especially restoration of the length of the fibula and maintaining reduction is almost impossible by closed methods. 5

Danis emphasized that the internal fixation should be so complete and rigid that the injured joint can be exercised in the early postoperative period. The AO principles for the treatment of ankle fractures were based on Danis recommendations and on biomechanical studies of the importance of the lateral malleolus and the syndesmosis for the stability of the ankle. ${ }^{6}$

Increased knowledge about the normal and post traumatic anatomy, function of the ankle joint has led to demands for exact reduction and rigid internal fixation of ankle fractures. It is difficult to satisfy these demands with closed, non-operative methods of treatment. Open reduction and internal fixation is therefore the standard treatment for displaced and unstable fractures about the ankle ${ }^{4}$. Cedell, Cotton C. L. and many other authors have reported better results after operative treatment as compared with closed methods. ${ }^{7}$

The surgical technique used in this present series contributes a precise method of open reduction and internal fixation by using dynamic compression plate or semi tubular plate and screws, malleolar screws, tension band wiring or a combination of these. Our experience of this method of fixation has given favourable results.

In the present study, thirty patients were operated for malleolar fracture of the ankle by semi tubular plate or dynamic compression plate and screws, malleolar screws, tension band wiring or combination of these. The data collected in the study are assessed and analyzed. The results are evaluated based on pain, range of movement at the ankle and subtalar joint, radiograph, activity and complications as per Weber's protocol. ${ }^{4}$

The rating as per the protocol was excellent, good or poor. Of the 30 patients there were 13 patients (43.3\%) with excellent results, 12 patients (40\%) with good results, 5 patients (16.6\%) had poor results.

The 13 patients fulfilled the criteria as per Weber's protocol and had a score of 0 . Taking this into consideration they were rated as excellent.

In 12 patients, slight pain with excess activity (+), slight diminution of range of movements at ankle and subtlar joint (SD), had normal work with restriction of strenuous activity (NW RSA) and there were no complications. 5 patients had a score of 1 and 7 patients had a score of 2. Taking all these criteria into consideration this group was rated as good.

Of the 5 poor results, one case was a compound fracture. The surgery was delayed in this patient due to the compound injury. At the 6 months, he had pain with normal activity, range of movement at ankle and subtalar joint was limited $>1 / 2$ of sound side. The fracture united by 16 weeks. Patient had normal work, but limited in his activity. This patient had infection as a complication and had a score of 10 and rated poor as per Weber's protocol. Compound injury, infection, delay in the treatment were the reasons for poor result.

One case was a 50 year old male with ankle dislocation. The surgery was delayed in this case. At the end of follow up, this patient had slight pain on excess activity (+), slight diminution of range of movements at the ankle and subtalar joint. Fracture united in 14 weeks and normal work with restriction of strenuous activity was present. The score was 4 and rated poor as per Weber's Protocol. Age of the patient, delay in the treatment and severe soft tissue injury were considered for the poor result. 
Another case was a 45 year old female. The patient at the end of 6 months had mild pain on excess activity, slight diminution of ankle and subtalar joint movements. The fracture united in 12 weeks. Patient had normal work with restriction of strenuous activity. The score was 3 and rated poor as per Weber's protocol. Age and being a female patient with tendency for osteoporosis were attributed for the poor result.

Another case was a compound fracture. The surgery was delayed in this case. At the end of the follow up, the patient had mild pain on excess activity, fracture united in 14 weeks. Slight diminution of ankle and subtalar joint movements was present, and had normal work with restriction of strenuous activity. The case was given a score of 4 and rated poor as per Weber's protocol. Fracture being compound and delay in the treatment were the reasons for the poor result.

Another case was a compound Tri malleolar fracture. The surgery was delayed in this case too. At the end of 6 months, the patient had mild pain on excess activity. Slight diminution of ankle and subtalar joint movements was there. Fracture united in 16 weeks. Patient had normal work with restriction of strenuous activity. This case had a score of 4 and was rated as poor as per Weber's protocol. Age of the patient, compound fracture, delay in the treatment and poor cooperation by the patient are attributed for the poor result.

The present study is based upon treatment for malleolar fractures and their results in 30 cases with a follow up of 6 months as shown in table 1.

\begin{tabular}{|l|c|}
\hline \multicolumn{1}{|c|}{ Series } & Follow up \\
\hline Johanne's Yde & 78 months \\
\hline ULF Lindsjo $^{8}$ & 48 months \\
\hline Richeerd S. Limbird $^{9}$ & 34 months \\
\hline Childress $^{2}$ months \\
\hline Listal $^{4}$ & 96 months \\
\hline Frieburg $^{4}$ & 60 months \\
\hline Gallen $^{4}$ & 67.5 months \\
\hline Bostman $^{10}$ & 12 months \\
\hline Yoblan $^{11}$ & 66 months \\
\hline Our study & 6 months \\
\hline \multicolumn{2}{|c|}{ Table 1 } \\
\hline
\end{tabular}

ULF Lindsjo has found in his series that osteoarthritis following ankle fracture were more common among the female patient and showed poor clinical results of treatment attributed to greater tendency to osteoporosis in menopausal women. ${ }^{8}$

Kristensen, Cedell, Danis et al have emphasized the significance of accurate reduction for a good result. ${ }^{7}$ With the exact restoration of the anatomy of the ankle joint, the biomechanical pre requisites for good function will be fulfilled. The best method of treatment for attaining the goal is an accurate open reduction and rigid interval fixation.

CONCLUSION: In the present study, 30 patients with malleolar fractures of ankle were surgically managed. The data was assessed, analyzed, evaluated and the following conclusions were drawn

- It is more common between 31 - 50 years. The mean age being 39.30 . 
- It is more common in males (63.3\%) than females (36.7 \%).

- Right side is more commonly involved than the left side.

- The most common cause of injury being RTA (63.3\%).

- $76.7 \%$ of the patients were having simple fractures.

- Type B Danis - Weber malleolar fractures were more common (50 \%).

- External rotation injury is the most common mechanism of injury.

- In the present study all the fractures united.

- $60 \%$ of the cases had no pain at the end of 6 month follow up.

- $63.3 \%$ of the cases had full range of motion at the ankle and subtalar joint.

- $66.7 \%$ of the cases were fully able to perform their job.

- One case had infection as a complication.

- $83.3 \%$ of the cases had excellent to good results. $16.6 \%$ of the cases had poor results.

- Delay in surgery, severe soft tissue injury, compound injury, infection, osteoporosis, poor cooperation for rehabilitation by the patient is attributed for the causes of poor results.

Surgical management of malleolar fractures of ankle is simple, effective and economical which can be carried out in a minimal basic orthopedic set up. It ensures restoration of anatomy and good function of the ankle joint.

\section{REFERENCES:}

1. Canale T.S. Fractures of the lower extremity. Cambell's operative Orthopaedics - Vol 3. $10^{\text {th }}$ ed, 2003: 2726 - 2740

2. Rhys H Thomas \& Timothy R Daniels. Ankle arthritis. J Bone Joint Surgery. Am, May 2003: 85:923-936.

3. Mats Bauer et al. Malleolar Fractures: Non-operative Versus Operative Treatment. Clin Orthop, 199: 17-26, 1985.

4. Hughes H. Weber. Evaluation of Ankle Fractures - Non Operative and Operative Treatment. Clinic, Ortho, 138:111, 1979.

5. Mitchell W.G, Shaftan G.W, Sclafani J.J. Mandatory open reduction: It's Role in Displaced Ankle Fractures. J. Trauma 19:602-615, 1979.

6. M.E. Muller, R. Schneider: AO Manual of Internal Fixation.

7. Cedell C.A, Wiberg G. Treatment of Eversion -Supination Fracture Of The Ankle (2nd Degree). Acta Chir. Scanz, 124:41-44, 1962.

8. Lindsjo, U.L.F. Operative Treatment of Ankle Fracture Dislocation, Clinic, Ortho, 199: 28, 1985.

9. Richard, S. Limbird. Laterally Communited Fracture Dislocation of Ankle. JBJS, 69a/6, 881, 1987.

10. Bostman 0, Hirvensalo E et al. Ankle Fractures treated using Biodegradable internal fixation, Clin Orthop, 238: 195-203, 1989.

11. Yablon. I.G., Heller. F.G, Shouse L. The Key Role of the Lateral Malleolus in Displaced Fractures of the Ankle. J. Bone Joint Surg., 59a:169, 1977. 


\section{ORIGINAL ARTICLE}
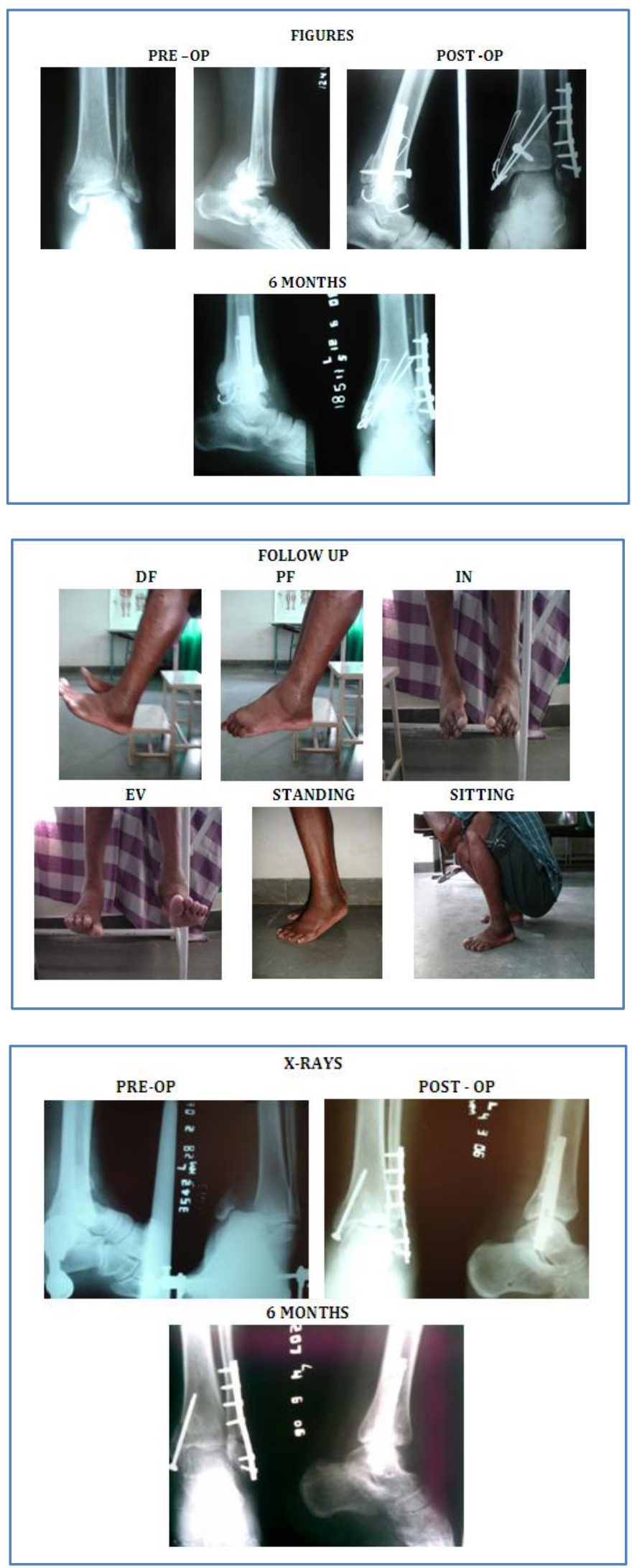


\section{ORIGINAL ARTICLE}
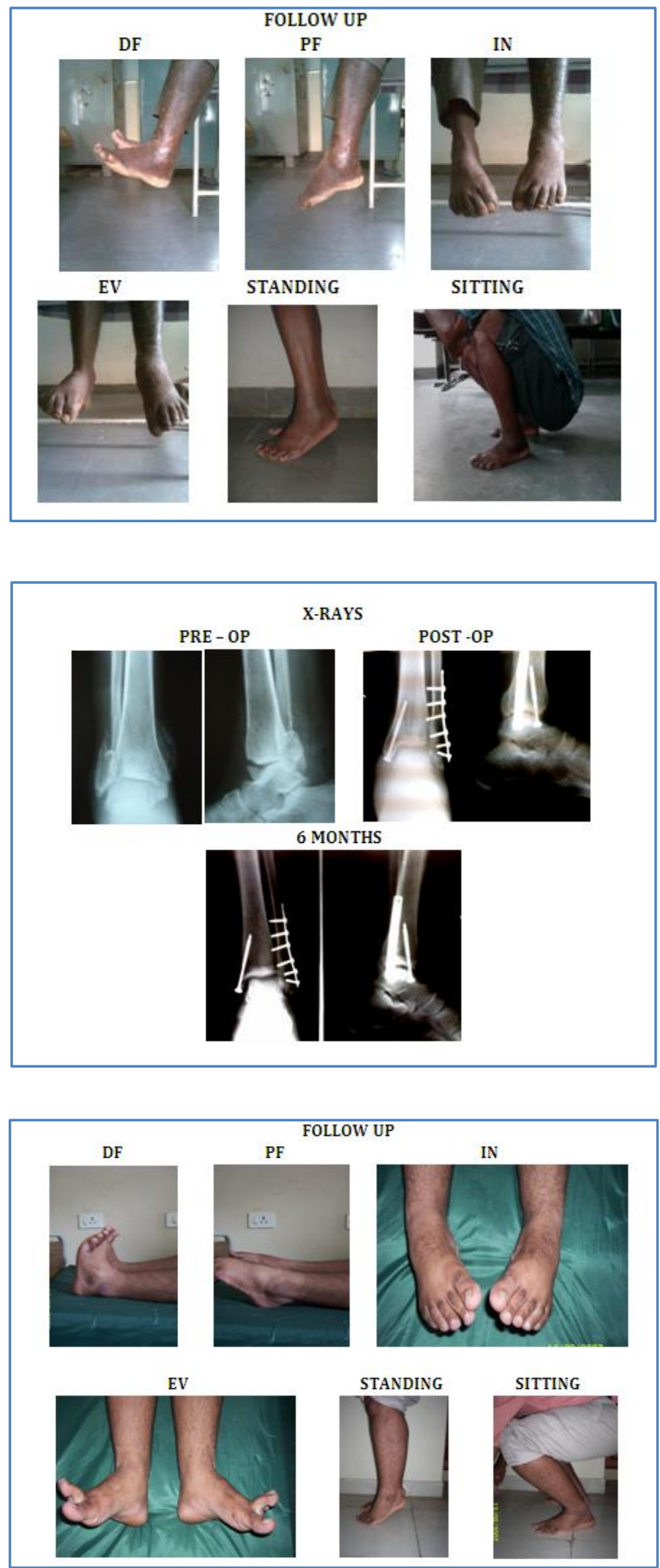


\begin{tabular}{|c|c|c|}
\hline Age in years & Number & $\mathbf{\%}$ \\
\hline $21-30$ & 8 & 26.7 \\
\hline $31-40$ & 9 & 30.0 \\
\hline $41-50$ & 9 & 30.0 \\
\hline$>50$ & 4 & 13.3 \\
\hline Total & 30 & 100.0 \\
\hline Mean \pm SD & \multicolumn{2}{|c|}{$39.30 \pm 11.72$} \\
\hline
\end{tabular}

Table 2: Age distribution of patients studied

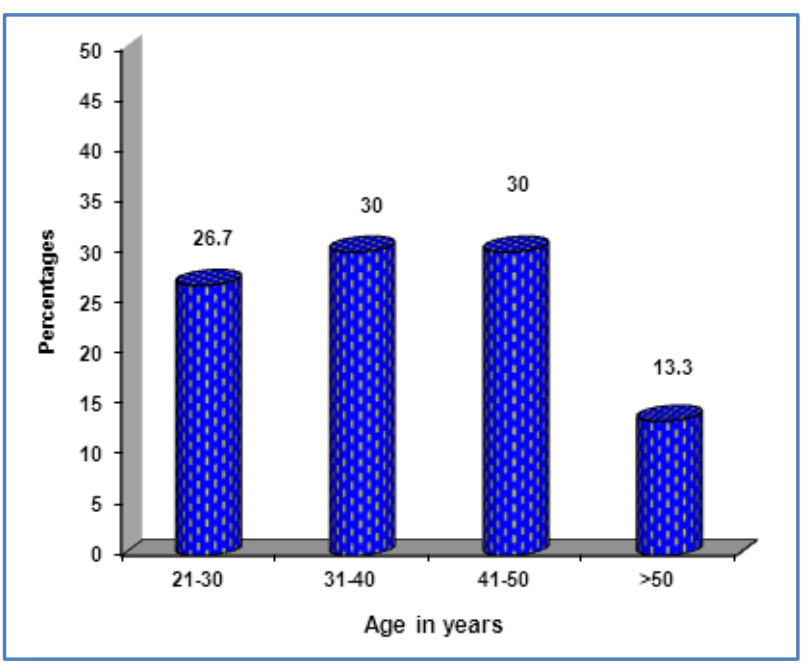

\section{Graph 1: Age distribution of patients studied}

\begin{tabular}{|c|c|c|}
\hline Mode of Injury & Number & $\%$ \\
\hline Fall & 11 & 36.7 \\
\hline RTA & 19 & 63.3 \\
\hline Total & 30 & 100.0 \\
\hline
\end{tabular}

\section{Table 3: Mode of Injury}

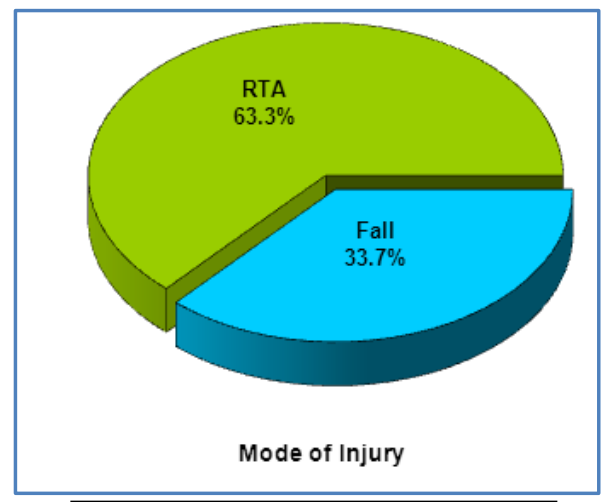

Graph 2: Mode of Injury 


\begin{tabular}{|c|c|c|}
\hline Simple/Compound & Number & $\%$ \\
\hline Simple & 23 & 76.7 \\
\hline Compound & 7 & 23.3 \\
\hline Total & 30 & 100.0 \\
\hline
\end{tabular}

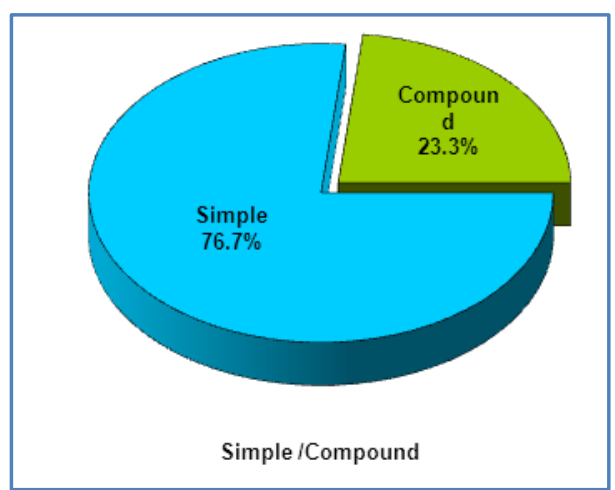

Graph 3: Simple/Compound

\begin{tabular}{|c|c|c|}
\hline Mechanism of Injury & Number & $\%$ \\
\hline Abduction & 3 & 10.0 \\
\hline Adduction & - & - \\
\hline Ab External rotation & 3 & 10.0 \\
\hline Add Internal Rotation & 9 & 30.0 \\
\hline External Rotation & 15 & 50.0 \\
\hline Total & 30 & 100.0 \\
\hline
\end{tabular}

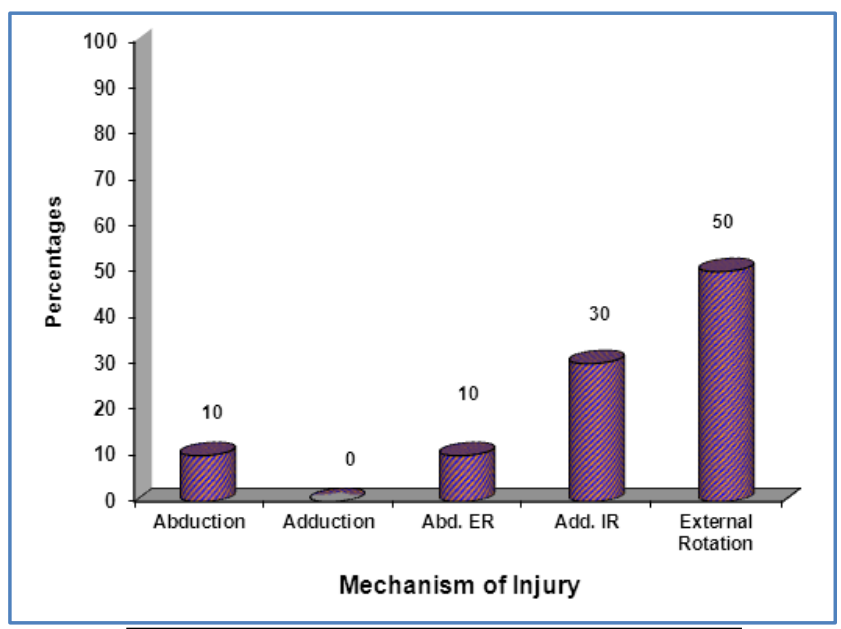

Graph 4: Mechanism of Injury 


\begin{tabular}{|l|c|c|}
\hline \multicolumn{1}{|c|}{ Surgical management } & Number & $\mathbf{\%}$ \\
\hline 1.lm-1/3tp, mm-ms & 8 & 26.7 \\
\hline 2.mm-tbw & 6 & 20.0 \\
\hline 3.lm-1/3tp, mm-tbw & 3 & 10.0 \\
\hline 4.mm-ms & 2 & 6.7 \\
\hline 5.mm-ms, pm-ms & 1 & 3.3 \\
\hline 6.fib-1/3 tp, dl repair & 1 & 3.3 \\
\hline 7.fib-1/3 tp,mm-ms pm-ms & 1 & 3.3 \\
\hline 8.lm-1/3tp, mm- ms & 1 & 3.3 \\
\hline 9.lm-1/3tp, mm- tbw & 1 & 3.3 \\
\hline 10.lm-1/3tp, mm-ms, sy-ss & 1 & 3.3 \\
\hline 11.lm-1/3tp, sy-ss & 1 & 3.3 \\
\hline 12.lm-1/3tp,mm-ms & 1 & 3.3 \\
\hline 13lm-1/3tp,mm-ms, & 1 & 3.3 \\
\hline 14.lm-1/3tp,mm-ms,pm-ms & 1 & 3.3 \\
\hline 15.lm-dcp, pm-ms & 1 & 3.3 \\
\hline \multicolumn{2}{|c|}{ Table 6: Surgical management } \\
\hline
\end{tabular}

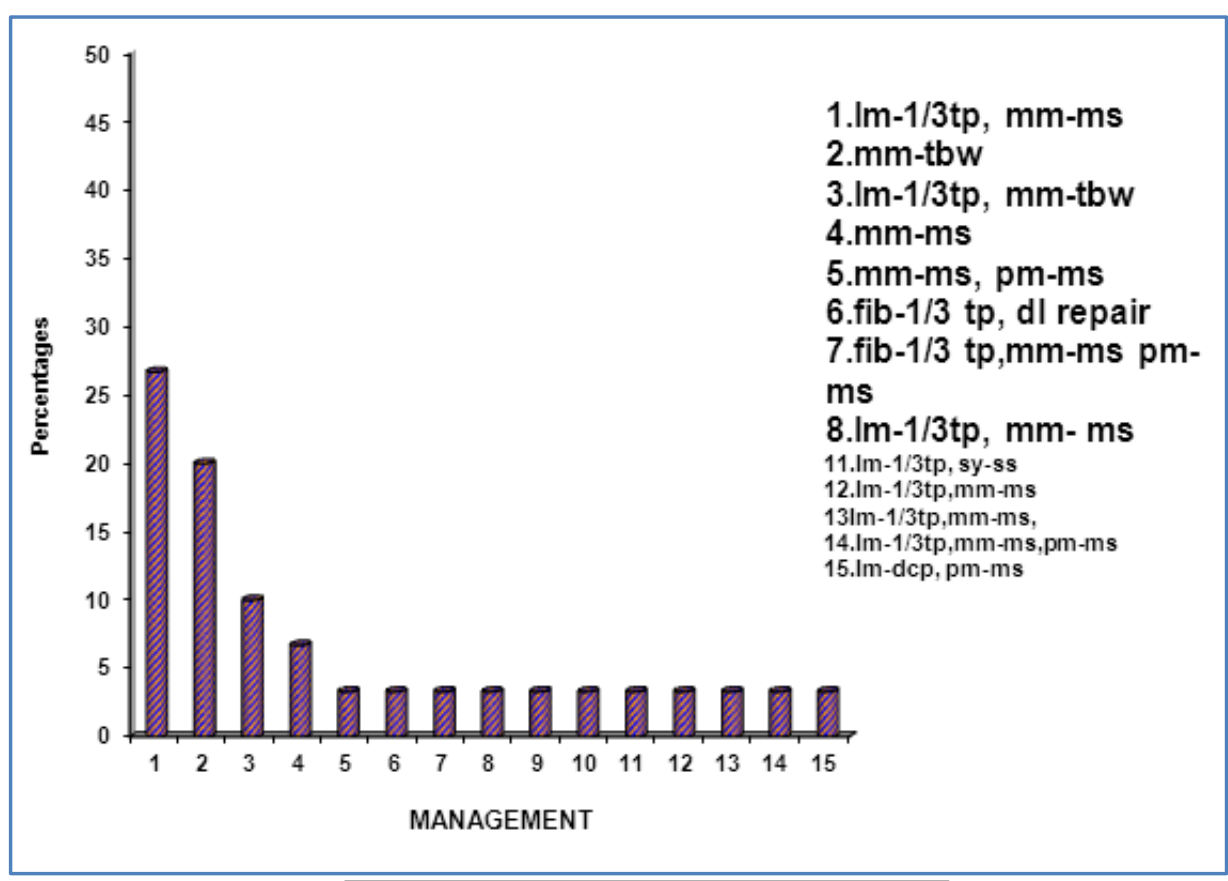

Graph 5: Surgical management 


\begin{tabular}{|l|c|c|c|}
\hline $\begin{array}{c}\text { Fracture union } \\
\text { in weeks }\end{array}$ & $\begin{array}{c}\text { Number } \\
\text { (n=30) }\end{array}$ & $\mathbf{\%}$ & $\mathbf{9 0 \% C I}$ \\
\hline$\leq 10$ weeks & 18 & 60.0 & $45.09-73.29$ \\
\hline$>10$ weeks & 12 & 40.0 & $26.71-54.94$ \\
\hline Mean \pm SD & $10.90 \pm 2.33$ & - \\
\hline
\end{tabular}

Table 7: Fracture union in weeks

All fractures united. In 18 cases union was achieved within 10 weeks. In 6 cases by 12 weeks, in 4 cases by 14 weeks and in 2 cases by 16 weeks.

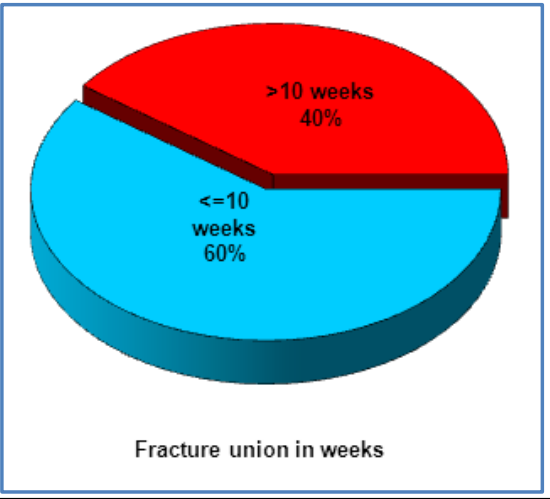

\section{Graph 6: Fracture union in weeks}

\begin{tabular}{|l|c|c|c|}
\hline \multicolumn{1}{|c|}{ Range of motion } & $\begin{array}{c}\text { Number } \\
(\mathbf{n = 3 0 )}\end{array}$ & $\mathbf{9}$ & $\mathbf{9 0 \% C I}$ \\
\hline Full range & 19 & 63.3 & $48.33-76.13$ \\
\hline Slight diminution & 10 & 33.3 & $21.08-48.34$ \\
\hline Limitation $<1 / 2$ of sound side & - & - & - \\
\hline Limitation $>1 / 2$ of sound side & 1 & 3.3 & $0.8-13.64$ \\
\hline Stiff foot & - & - & - \\
\hline
\end{tabular}

\section{Table 8: Range of motion}

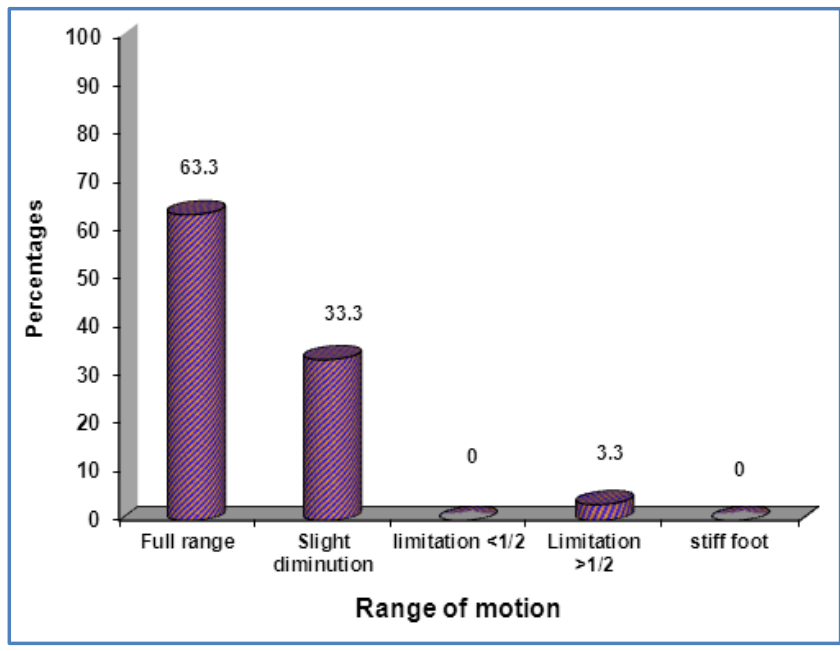

\section{Graph 7: Range of motion}




\section{ORIGINAL ARTICLE}

\begin{tabular}{|l|c|c|c|}
\hline Complications & $\begin{array}{c}\text { Number } \\
(\mathbf{n = 3 0 )}\end{array}$ & $\mathbf{\%}$ & $\mathbf{9 0 \% C I}$ \\
\hline Absent & 29 & 96.67 & $86.67-99.25$ \\
\hline Present & 1 & 3.3 & $0.8-13.64$ \\
\hline Infection & 1 & 3.3 & $0.8-13.64$ \\
\hline Swelling & - & - & - \\
\hline Deformity & - & - & - \\
\hline \multicolumn{4}{|r|}{ Table 9: Complications } \\
\hline
\end{tabular}

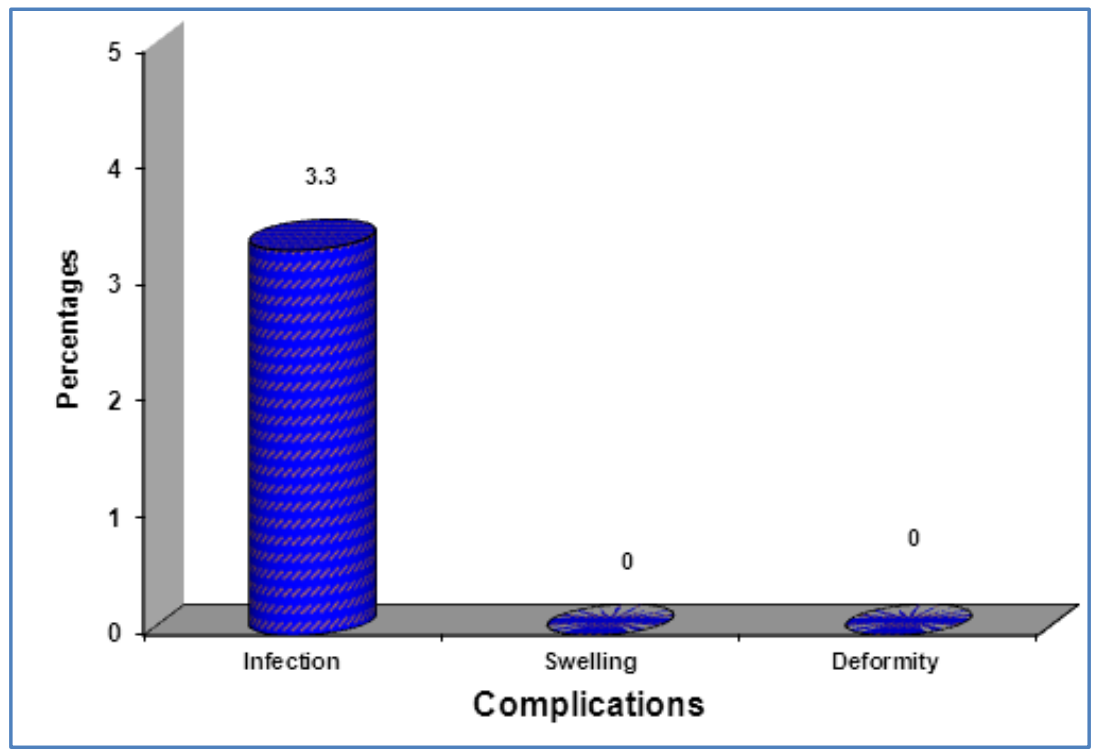

Graph 8: Complications

\begin{tabular}{|l|c|c|}
\hline $\begin{array}{c}\text { Ratings of management } \\
\text { outcome }\end{array}$ & Number (n=30) & \% \\
\hline Excellent & 13 & 43.3 \\
\hline Good & 12 & 40 \\
\hline Poor & 5 & 16.6 \\
\hline \multirow{2}{*}{ Inference } & $\begin{array}{l}\text { 83.3\% of the patients have been rated as } \\
\text { Excellent - Good rating with 90\%CI (73.40-93.87) } \\
\text { Which is statistically significant. }\end{array}$ \\
\hline \multicolumn{2}{|c|}{ Table 10: Ratings of management outcome } \\
\hline
\end{tabular}




\section{ORIGINAL ARTICLE}

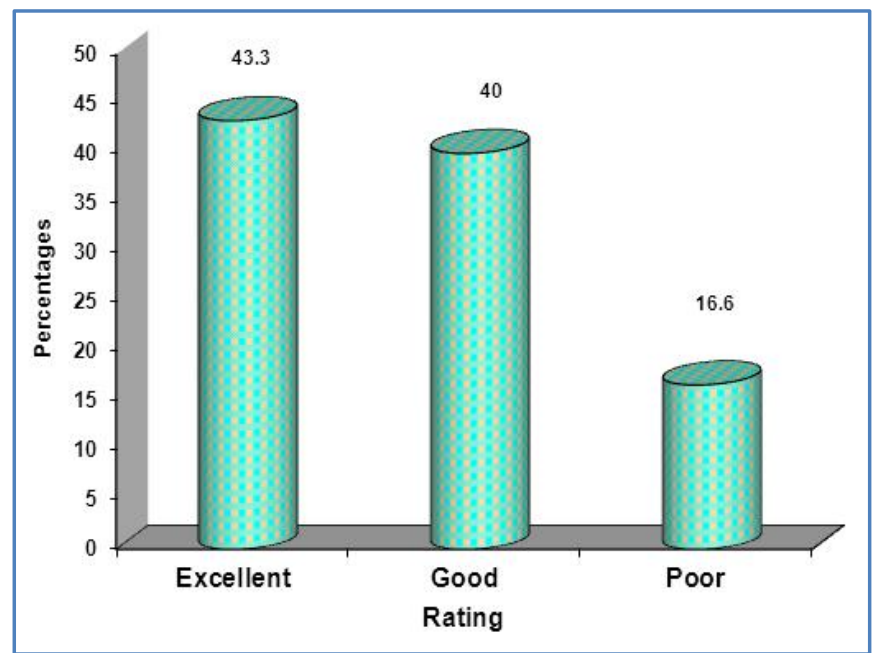

Graph 9: Ratings of management outcome

\begin{tabular}{|c|c|c|}
\hline Final outcome & Excellent-Good (\%) & Poor (\%) \\
\hline Type A & 88.8 & 11.1 \\
\hline Type B & 80.0 & 20.0 \\
\hline Type C & 83.3 & 16.6 \\
\hline \multicolumn{3}{|c|}{ Table 11: Final outcome } \\
\hline
\end{tabular}

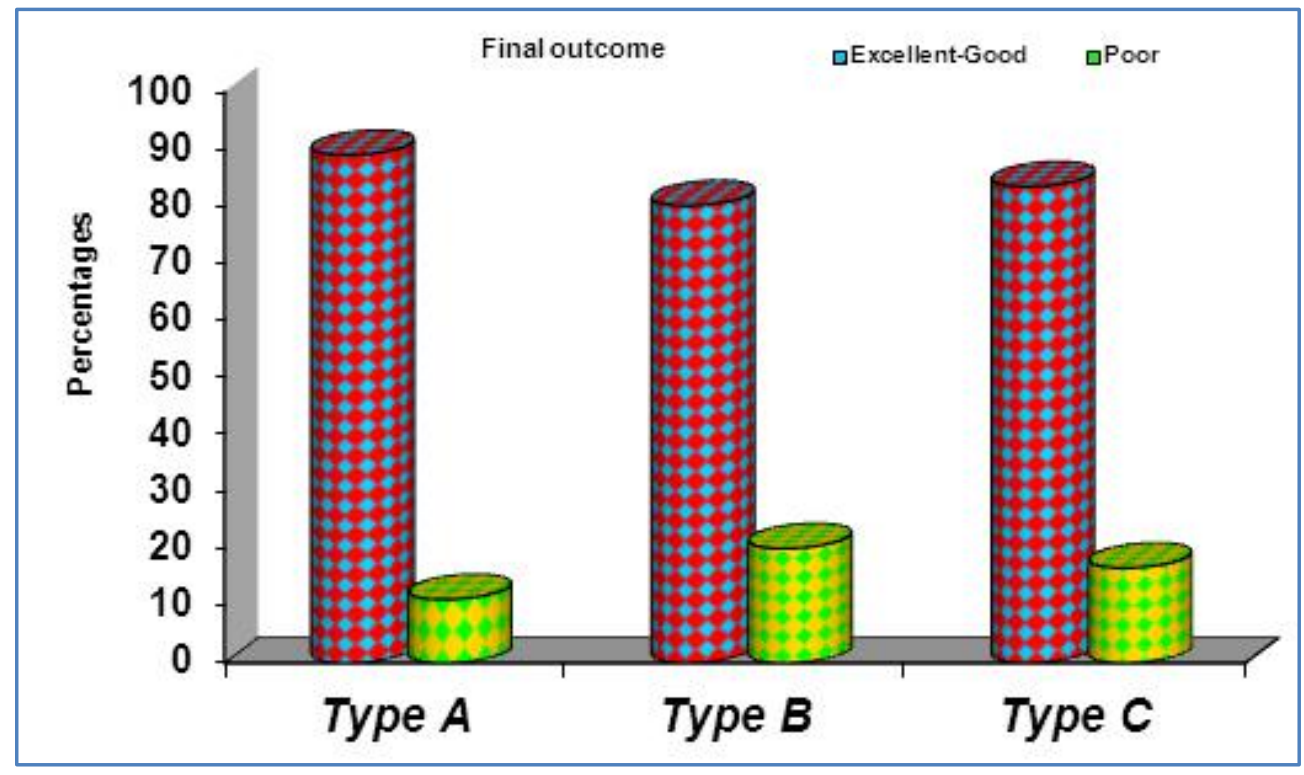

Graph 10: Final outcome chart 


\section{ORIGINAL ARTICLE}

\section{AUTHORS:}

1. Srinivas Nagendra G.

2. Prabhakar Venkataramana

3. Siddarth Mahesh

\section{PARTICULARS OF CONTRIBUTORS:}

1. Assistant Professor, Department of Orthopaedics, Sapthagiri Medical College \& Hospital.

2. Senior Resident, Department of Orthopaedics, Sapthagiri Medical College \& Hospital.

3. Assistant Professor, Department of Orthopaedics, Sapthagiri Medical College \& Hospital.

\section{NAME ADDRESS EMAIL ID OF THE CORRESPONDING AUTHOR:}

Dr. Prabhakar V, \#55, Rajiv Gandhi Road, J. P. Nagar, $6^{\text {th }}$ Phase Post, Jaraganahalli, Bangalore - 560078.

E-mail: dr.prabhakar.venkat@gmail.com

Date of Submission: 27/02/2014.

Date of Peer Review: 28/02/2014.

Date of Acceptance: 07/03/2014.

Date of Publishing: 18/03/2014. 